\title{
Pulsed Doppler Evaluation of Right Ventricular Diastolic Filling in Children with Pulmonary Valve Stenosis Before and After Balloon Valvuloplasty
}

\author{
Roger P. Vermilion, MD, A. Rebecca Snider, MD, Jon N. Meliones, MD, Jane Peters, \\ and Lyne Merida-Asmus
}

To assess right ventricular (RV) diastolic filling in children with pulmonary stenosis (PS), 14 patients (mean age 5.1 years) were examined immediately before and after pulmonary balloon valvuloplasty. Fourteen normal children (mean age 4.8 years) were also studied. From the tricuspid valve infiow Doppler study, the following measurements were made at peak inspiration: peak velocities at rapid filling (peak $E$ ) and during atrial contraction (peak A), ratio of peak $E$ to peak A velocitles, RV peak filling rate normalized for stroke volume, tofal area under the Doppler curve, percent of the total Doppler area occurring in the first third of diastole $(0.33$ area fraction), percent of the total area occurring under the $E$ wave ( $E$ area fraction), percent of the total area occurring under the $A$ wave (A area fraction) and the ratio of $E$ area to $A$ area. Before balloon valvuloplasty, the patients with PS had higher peak $A$ velocity $(0.64 \pm 0.28$ vs $0.39 \pm 0.08 \mathrm{~m} / \mathrm{s})$, lower E/A velocity ratio ( $1.11 \pm 0.52$ vs $1.76 \pm$ $0.45)$, lower 0.33 area fraction $(0.34 \pm 0.14$ vs $0.49 \pm 0.08)$, higher $A$ area fraction (0.45 \pm 0.21 vs $0.27 \pm 0.09)$ and lower $E / A$ area ratio $(1.73 \pm$ 1.05 vs $2.96 \pm 1.14$ ) than the normal subjects (p $<0.01$ ). In patients before and after balloon valvuloplasty, there was a significant difference in RV outflow gradient (71 \pm 35 vs $28 \pm 15 \mathrm{~mm} \mathrm{Hg}$ ), but there was no change in any Doppler index. Thus, patlents with PS have abnormal diastolic filling with decreased filling in early diastole and increased filling during atrial contraction. These abnormalities are unchanged immediately after successful relief of RV outflow obstruction, suggesting that hypertrophy rather than afterload mismatch is the primary determinant of the impaired relaxation.

(Am J Cardiol 1990;66:79-84)

\footnotetext{
From the Department of Pediatrics, C.S. Mott Children's Hospital, University of Michigan Medical Center, Ann Arbor, Michigan. Manuscript received December 19, 1989; revised manuscript received February 21,1990 , and accepted February 22.

Address for reprints: Roger P. Vermilion, MD, F1609, C.S. Mott Children's Hospital, University of Michigan Medical Center. Ann Arbor, Michigan 48109-0204.
}

$\mathrm{P}$ ulsed Doppler echocardiography has been used to assess left ventricular (LV) diastolic filling in a variety of diseases including systemic hypertension, LV outflow obstruction, hypertrophic cardiomyopathy and coronary artery disease. ${ }^{1-8}$ Mitral valve Doppler indexes of LV filling have correlated closely with those measured from cineangiography ${ }^{9}$ and radionuclide angiography. ${ }^{10,11}$ From the mitral valve Doppler recording, peak flow velocities, filling rates and the proportion of filling in the various phases of diastole can be measured for the left ventricle. For the right ventricle, similar diastolic filling indexes can be derived using the tricuspid valve Doppler recording. ${ }^{12}$ Normal values for the tricuspid valve Doppler indexes have been reported for the fetus, newborn infant and child. ${ }^{13-17}$ These indexes, however, have not yet been used to assess right ventricular (RV) diastolic filling in children with cardiac defects that might affect RV relaxation or compliance, or both.

In this study, we hypothesized that children with RV hypertrophy caused by valvular pulmonary stenosis (PS) have abnormalities of RV diastolic filling. Further, if these abnormalities were caused by hypertrophy alone, then RV diastolic filling should be unchanged immediately after successful relief of the systolic pressure overload. To test this hypothesis, we assessed RV diastolic filling using pulsed Doppler echocardiography in 14 children with PS before and immediately after balloon valvuloplasty.

\section{METHODS}

Patients: The study comprised 14 children with PS and 14 age-matched, normal control subjects. The control group consisted of 5 girls and 9 boys with no evidence of heart disease on physical examination or by 2 dimensional and Doppler echocardiography. They were 0.5 to 16 years old (mean 4.8 ) and weighed 8.3 to $64 \mathrm{~kg}$ (mean 21). The patient group comprised 6 girls and 8 boys who were randomly selected from all children with PS undergoing cardiac catheterization between August 1985 and September 1989. Selection criteria included: (1) presence of PS severe enough to warrant treatment with balloon valvuloplasty, (2) absence of additional congenital defects such as tricuspid stenosis or left-toright shunts that might alter the tricuspid valve Doppler recording and (3) absence of significant tricuspid or pulmonary regurgitation by Doppler examination before and after valvuloplasty. The patient group was 0.4 
TABLE I Doppler Measurements in Patients with Pulmonary Stenosis Before and After Balloon Valvuloplasty and in Normal Subjects

\begin{tabular}{|c|c|c|c|c|c|c|c|c|c|c|c|c|c|c|c|c|c|c|c|c|c|}
\hline & \multirow{2}{*}{$\begin{array}{l}\text { Age } \\
\text { (yrs) }\end{array}$} & \multicolumn{2}{|c|}{ PeakE } & \multicolumn{2}{|c|}{ Peak A } & \multicolumn{2}{|c|}{ PeakE/A } & \multicolumn{2}{|l|}{$\mathrm{TA}$} & \multicolumn{2}{|c|}{$\begin{array}{l}0.33 \\
\text { area/TA }\end{array}$} & \multicolumn{2}{|c|}{$\mathrm{E}$ area/TA } & \multicolumn{2}{|c|}{ A area/TA } & \multicolumn{2}{|c|}{$E / A$ area } & \multicolumn{2}{|c|}{ PFR-SV } & \multicolumn{2}{|c|}{$\begin{array}{l}\text { HR } \\
\text { (beats/min) }\end{array}$} \\
\hline & & Pre & Post & Pre & Post & Pre & Post & Pre & Post & Pre & Post & Pre & Post & Pre & Post & Pre & Post & Pre & Post & Pre & Post \\
\hline \multicolumn{22}{|c|}{ Patients } \\
\hline 1 & 18.1 & 0.7 & 0.74 & 0.49 & 0.59 & 1.44 & 1.25 & 0.18 & 0.19 & 0.44 & 0.39 & 0.67 & 0.7 & 0.34 & 0.31 & 1.99 & 2.24 & 3.89 & 3.89 & 67 & 75 \\
\hline 2 & 2.5 & 0.82 & 0.78 & 0.54 & 0.6 & 1.53 & 1.31 & 0.12 & 0.09 & 0.4 & 0.34 & 0.65 & 0.62 & 0.37 & 0.32 & 1.83 & 1.92 & 6.83 & 8.67 & 132 & 120 \\
\hline 3 & 2.7 & 0.73 & 0.75 & 0.76 & 0.86 & 0.98 & 0.87 & 0.1 & 0.17 & 0.29 & 0.23 & 0.56 & 0.6 & 0.44 & 0.49 & 1.3 & 1.23 & 7.3 & 4.41 & 104 & 89 \\
\hline 4 & 6.3 & 0.64 & 0.61 & 0.28 & 0.39 & 2.31 & 1.57 & 0.1 & 0.12 & 0.62 & 0.43 & 0.75 & 0.71 & 0.2 & 0.36 & 4.25 & 2.01 & 6.4 & 5.08 & 78 & 92 \\
\hline 5 & 3.8 & 0.66 & 0.62 & 0.71 & 0.64 & 0.93 & 0.97 & 0.17 & 0.16 & 0.28 & 0.32 & 0.61 & 0.66 & 0.43 & 0.42 & 1.41 & 1.57 & 3.88 & 3.88 & 85 & 84 \\
\hline 6 & 14.7 & 0.48 & 0.63 & 0.43 & 0.47 & 1.14 & 1.33 & 0.14 & 0.18 & 0.4 & 0.42 & 0.68 & 0.69 & 0.3 & 0.3 & 2.38 & 2.31 & 3.43 & 3.5 & 64 & 65 \\
\hline 7 & 1.1 & 0.72 & 0.77 & 0.82 & 1.05 & 0.87 & 0.73 & 0.14 & 0.13 & 0.3 & 0.28 & 0.6 & 0.49 & 0.47 & 0.68 & 1.3 & 0.74 & 5.14 & 5.92 & 100 & 116 \\
\hline 8 & 0.4 & 0.49 & 0.48 & 0.58 & 0.67 & 0.84 & 0.72 & 0.09 & 0.1 & 0.32 & 0.24 & 0.53 & 0.5 & 0.61 & 0.64 & 0.88 & 0.78 & 5.44 & 4.8 & 116 & 116 \\
\hline 9 & 1.2 & 0.49 & 0.53 & 0.66 & 0.63 & 0.75 & 0.85 & 0.08 & 0.11 & 0.24 & 0.26 & 0.46 & 0.49 & 0.59 & 0.6 & 0.78 & 0.82 & 6.13 & 4.82 & 109 & 101 \\
\hline 10 & 7.6 & 0.86 & 0.54 & 0.6 & 0.46 & 1.45 & 1.19 & 0.15 & 0.09 & 0.42 & 0.43 & 0.69 & 0.64 & 0.28 & 0.35 & 2.6 & 1.86 & 5.73 & 6 & 81 & 77 \\
\hline 11 & 6.5 & 0.47 & 0.38 & 0.41 & 0.54 & 1.13 & 0.71 & 0.08 & 0.08 & 0.41 & 0.3 & 0.68 & 0.42 & 0.29 & 0.58 & 2.39 & 0.73 & 5.88 & 4.75 & 80 & 93 \\
\hline 12 & 1.5 & 0.65 & 0.55 & 0.77 & 0.78 & 0.84 & 0.7 & 0.09 & 0.09 & 0.27 & 0.2 & 0.47 & 0.46 & 0.65 & 0.67 & 0.74 & 0.68 & 7.22 & 6.11 & 119 & 114 \\
\hline 13 & 0.7 & 0 & 0 & 1.44 & 1.59 & 0 & 0 & 0.12 & 0.11 & 0 & 0 & 0 & 0 & 1 & 1 & 0 & 0 & 0 & 0 & 162 & 151 \\
\hline 14 & 3.7 & 0.6 & 0.81 & 0.44 & 0.71 & 1.38 & 1.13 & 0.09 & 0.11 & 0.24 & 0.24 & 0.69 & 0.6 & 0.3 & 0.51 & 2.31 & 1.19 & 6.67 & 7.36 & 92 & 114 \\
\hline Mean & 5.1 & 0.59 & 0.59 & 0.64 & 0.71 & 1.11 & 0.95 & 0.12 & 0.12 & 0.32 & 0.28 & 0.57 & 0.54 & 0.45 & 0.52 & 1.73 & 1.29 & 5.28 & 4.94 & 99.2 & 100.5 \\
\hline \multicolumn{22}{|c|}{ Control subjects } \\
\hline I & 0.5 & 0.58 & & 0.3 & & 1.97 & & 0.07 & & 0.52 & & 0.68 & & 0.32 & & 2.15 & & 8.29 & & 115 & \\
\hline 2 & 0.7 & 0.65 & & 0.34 & & 1.91 & & 0.09 & & 0.48 & & 0.74 & & 0.25 & & 3.04 & & 7.22 & & 96 & \\
\hline 3 & 1 & 0.7 & & 0.48 & & 1.47 & & 0.09 & & 0.38 & & 0.67 & & 0.42 & & 1.63 & & 7.78 & & 106 & \\
\hline 4 & 1 & 0.6 & & 0.45 & & 1.34 & & 0.09 & & 0.37 & & 0.68 & & 0.33 & & 2.11 & & 6.67 & & 108 & \\
\hline 5 & 1 & 0.74 & & 0.5 & & 1.46 & & 0.1 & & 0.39 & & 0.64 & & 0.43 & & 1.49 & & 7.4 & & 108 & \\
\hline 6 & 2.6 & 0.73 & & 0.37 & & 2.03 & & 0.09 & & 0.51 & & 0.72 & & 0.23 & & 3.41 & & 8.11 & & 93 & \\
\hline 7 & 3.5 & 0.75 & & 0.46 & & 1.61 & & 0.13 & & 0.54 & & 0.67 & & 0.3 & & 2.25 & & 5.77 & & 80 & \\
\hline 8 & 4.5 & 0.4 & & 0.37 & & 1.1 & & 0.09 & & 0.43 & & 0.6 & & 0.32 & & 1.91 & & 4.44 & & 70 & \\
\hline 9 & 5 & 0.78 & & 0.5 & & 1.57 & & 0.14 & & 0.52 & & 0.69 & & 0.26 & & 2.67 & & 5.57 & & 88 & \\
\hline 10 & 6 & 0.65 & & 0.36 & & 1.86 & & 0.13 & & 0.46 & & 0.73 & & 0.19 & & 3.94 & & 5 & & 72 & \\
\hline 11 & 6.5 & 0.65 & & 0.35 & & 1.86 & & 0.12 & & 0.62 & & 0.7 & & 0.19 & & 3.78 & & 5.42 & & 86 & \\
\hline 12 & 7.3 & 0.64 & & 0.38 & & 1.72 & & 0.11 & & 0.43 & & 0.74 & & 0.23 & & 3.47 & & 5.82 & & 83 & \\
\hline 13 & 12 & 0.6 & & 0.35 & & 1.74 & & 0.1 & & 0.52 & & 0.71 & & 0.18 & & 4.12 & & 6 & & 75 & \\
\hline 14 & 16 & 0.76 & & 0.25 & & 3.05 & & 0.13 & & 0.65 & & 0.8 & & 0.15 & & 5.48 & & 5.85 & & 73 & \\
\hline Mean & 4.8 & 0.66 & & 0.39 & & 1.76 & & 0.11 & & 0.49 & & 0.70 & & 0.27 & & 2.96 & & 6.4 & & 89.5 & \\
\hline
\end{tabular}

to 18 years old (mean 5.1 ) and weighed 7.2 to $82 \mathrm{~kg}$ (mean 21.6).

Cardiac catheterization: The patient group underwent right- and left-sided cardiac catheterization after being sedated with a combination of morphine sulfate, diphenhydramine and chloral hydrate except for $1 \mathrm{pa}-$ tient who received ketamine and medazolam. Pcak-topeak pressure gradients across the obstruction and thermodilution cardiac indexes were measured before and after balloon dilatation.

Echocardiographic examination: All study participants underwent a range-gated pulsed Doppler examination of the RV inflow a maximum of 1 day before and 1 day after balloon valvuloplasty. Tricuspid valve Doppler examinations were obtained from the parasternal short-axis or apical 4-chamber view. The sample volume was positioned so as to record the maximum velocities through the valve (usually near the tips of the leaflets). Based on previous studies using simultaneous thermister and tricuspid valve Doppler recordings, the velocities through the tricuspid valve vary significantly throughout the respiratory cycle with maximal velocities occurring at peak inspiration..$^{15}$ Therefore, to obtain all Doppler measurements at a standard time in the respiratory cycle, only those beats recorded at peak inspiration were used.
From the Doppler spectral recordings, the peak velocities during rapid ventricular filling (peak E) and during atrial contraction (peak $A$ ) were measured and the ratio of peak $E$ to peak $A$ velocities was calculated. To investigate the Doppler patterns of RV filling, the following areas under the Doppler spectral tracing were mcasurcd: (1) the total area under the velocity envelope throughout diastole; (2) the area under the velocity curve for the first $33 \%$ of diastole $(0.33$ area); (3) the E area, or the triangular area formed by extrapolating a straight line down from the peak $E$ velocity to the baseline; and (4) the A area, or the triangular area formed by extrapolating a straight line down from the peak $\mathrm{A}$ velocity to the baseline. ${ }^{1}$ To determine the percent of the total velocity envelope occupied by the individual areas, the area or filling fractions were calculated as the individual areas divided by the total area under the Doppler tracing. Also, the ratio of the $\mathrm{E}$ and $\mathrm{A}$ areas was calculated. The peak filling rate normalized for stroke volume was calculated as the peak $\mathrm{E}$ velocity divided by the total velocity time integral. ${ }^{18}$

All Doppler examinations were recorded at a paper speed of $100 \mathrm{~mm} / \mathrm{s}$. The Doppler areas were traced from the paper recordings using a digitizing tablet with a crosswire cursor, a personal computer and commercially-available computer software (Freeland Medical 
Systems). The Doppler velocities and areas were measured by tracing the outermost border of the spectral recordings.

Statistical analysis: Three cardiac cycles were averaged to obtain each Doppler value. Statistical comparisons between the control and patient groups and between the patient group before and after valvuloplasty were made using paired $t$ tests. A 2-tailed $\mathrm{p}$ value of $<0.01$ was used to indicate a significant intergroup difference. All values are mean \pm standard deviation.

\section{RESULTS}

Patients: The patient group and the control group did not differ in age, weight or heart rate. At cardiac catheterization, all members of the patient group had successful relief of PS with balloon valvuloplasty. The peak-to-peak systolic pressure gradient before balloon valvuloplasty ( $71 \pm 35 \mathrm{~mm} \mathrm{Hg}$ ) was significantly higher than that after valvuloplasty $(28 \pm 15 \mathrm{~mm} \mathrm{Hg}$, p $<0.0005)$. Before and after balloon valvuloplasty, the cardiac index was unchanged $(3.5 \pm 0.7$ vs $3.7 \pm 0.8$ liters $/ \mathrm{min} / \mathrm{m}^{2}, \mathrm{p}=0.41$ ) and the RV end-diastolic pressure was lower $(11.1 \pm 2.5$ vs $8.6 \pm 2.0 \mathrm{~mm} \mathrm{Hg}$, p $<0.005$ ).

Doppler echocardiographic studies: Pulsed Doppler measurements for each individual patient before and after balloon valvuloplasty and for each control subject are listed in Table I.

COMPARISONS OF NORMAL SUBJECTS AND PATIENTS WITH PULMONARY STENOSIS BEFORE BALLOON VALVULOPLASTY: Mcan valucs for the Doppler measurcments of the normal subjects and the patient group before balloon valvuloplasty are listed in Table II. Figure 1 shows a typical Doppler recording from the patient group and from a control subject for comparison. The patient group had a much higher peak A velocity than the control group and no significant difference in peak $\mathrm{E}$ velocity; therefore, the ratio of peak $E$ to peak $A$ velocities was significantly lower in the patient group. In the patient group, the

TABLE II Tricuspid Valve Doppler Measurements in Normal Subjects and Patients with Pulmonary Stenosis Before Balloon Valvuloplasty

\begin{tabular}{|c|c|c|c|}
\hline Measurement & $\begin{array}{l}\text { Numitiä } \\
\text { Subjects }\end{array}$ & $\begin{array}{l}\text { Pátients } \\
\text { Before Balloon }\end{array}$ & P Value \\
\hline Peak E (m/s) & $0.66 \pm 0.10$ & $0.59 \pm 0.21$ & 0.28 \\
\hline Peak A (m/s) & $0.39 \pm 0.08$ & $0.64 \pm 0.28$ & $0.006 *$ \\
\hline PeakE/Peak A & $1.76 \pm 0.45$ & $1.11 \pm 0.52$ & $0.002 *$ \\
\hline Total area $(\mathrm{m})$ & $0.11 \pm 0.02$ & $0.12 \pm 0.03$ & 0.33 \\
\hline 0.33 area $(\mathrm{m})$ & $0.05 \pm 0.02$ & $0.04 \pm 0.02$ & 0.28 \\
\hline 0.33 area fraction & $0.49 \pm 0.08$ & $0.34 \pm 0.14$ & $0.007 *$ \\
\hline $\mathrm{E}$ area $(\mathrm{m})$ & $0.07 \pm 0.02$ & $0.07 \pm 0.03$ & 0.85 \\
\hline$E$ area fraction & $0.70 \pm 0.05$ & $0.57 \pm 0.19$ & 0.03 \\
\hline A area $(m)$ & $0.03 \pm 0.01$ & $0.05 \pm 0.03$ & $0.005^{*}$ \\
\hline A area fraction & $0.27 \pm 0.09$ & $0.45 \pm 0.21$ & $0.01 *$ \\
\hline E area / A area & $2.96 \pm 1.14$ & $1.73 \pm 1.05$ & $0.009 *$ \\
\hline $\operatorname{PFR}-S V(S V / s)$ & $6.38 \pm 1.20$ & $5.28 \pm 1.96$ & 0.12 \\
\hline Heart rate (beats $/ \mathrm{min}$ ) & $90 \pm 15$ & $99 \pm 27$ & 0.33 \\
\hline
\end{tabular}

TABLE III Tricuspid Valve Doppler Measurements in Patients with Pulmonary Stenosis Before and After Balloon Valvuloplasty

\begin{tabular}{|c|c|c|c|}
\hline Measurement & $\begin{array}{l}\text { Patients } \\
\text { Before Balloon }\end{array}$ & $\begin{array}{l}\text { Patients } \\
\text { After Balloon }\end{array}$ & PValue \\
\hline PeakE (m/s) & $0.59 \pm 0.21$ & $0.59 \pm 0.21$ & 0.8 \\
\hline $\operatorname{PeakA}(\mathrm{m} / \mathrm{s})$ & $0.64 \pm 0.28$ & $0.71 \pm 0.31$ & 0.02 \\
\hline PeakE/PeakA & $1.11 \pm 0.52$ & $0.95 \pm 0.39$ & 0.02 \\
\hline Total area $(\mathrm{m})$ & $0.12 \pm 0.03$ & $0.12 \pm 0.04$ & 0.51 \\
\hline $0.33 \operatorname{area}(\mathrm{m})$ & $0.04 \pm 0.02$ & $0.05 \pm 0.03$ & 0.63 \\
\hline 0.33 area fraction & $0.34 \pm 0.14$ & $0.29+0.11$ & 0.02 \\
\hline Earea $(m)$ & $0.07 \pm 0.03$ & $0.71 \pm 0.04$ & 0.91 \\
\hline E area fraction & $0.57 \pm 0.19$ & $0.54 \pm 0.18$ & 0.15 \\
\hline Aarea $(\mathrm{m})$ & $0.05 \pm 0.03$ & $0.06 \pm 0.02$ & 0.06 \\
\hline A area fraction & $0.45 \pm 0.21$ & $0.52 \pm 0.20$ & 0.03 \\
\hline E area/A area & $1.73 \pm 1.05$ & $1.29 \pm 0.70$ & 0.05 \\
\hline PFR-SV (SV/s) & $5.28 \pm 1.96$ & $4.94 \pm 2.00$ & 0.3 \\
\hline Heart rate (beats/min) & $99 \pm 27$ & $101 \pm 23$ & 0.68 \\
\hline
\end{tabular}

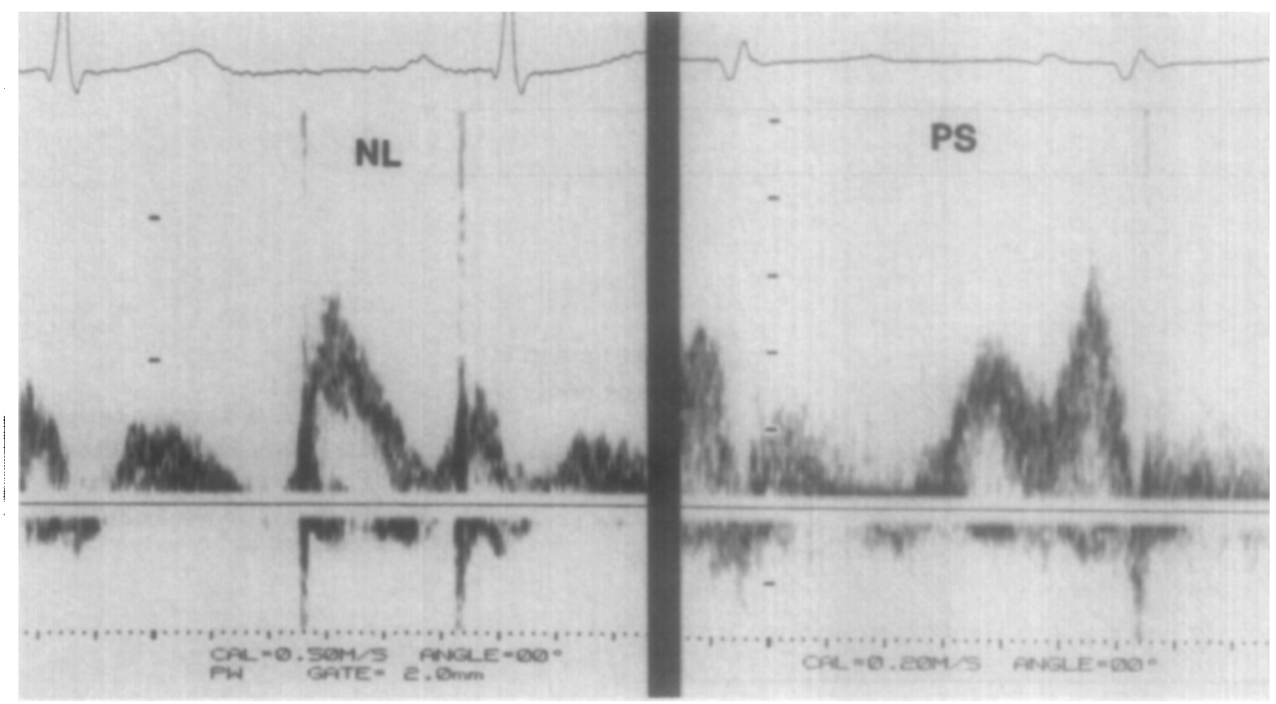

FIGURE 1. Tricuspid valve Doppler recordings from a patient with pulmonary stenosis (PS) (right) and an age-matched normal (NL) subject (left). Note the increased velocity during atrial contraction and the larger portion of the Doppler curve occurring in late diastole in the patient with PS. 
percent of the total Doppler area occurring in the first third of diastole was significantly lower, and the percent of the total Doppler area occurring under the A wave was significantly higher. The percent of the total Doppler area occurring under the $\mathrm{E}$ wave was not significantly different between the 2 groups; therefore, the ratio of $\mathrm{E}$ area to $\mathrm{A}$ area was lower in the patient group.
There was no significant difference in normalized peak filling rate between the 2 groups, although the patient group tended to have slightly lower peak filling rates.

COMPARISONS OF PATIENTS WITH PULMONARY STENOSIS BEFORE AND AFTER BALLOON VALVULOPLASTY: No differences were observed in any Doppler velocities, area frac-
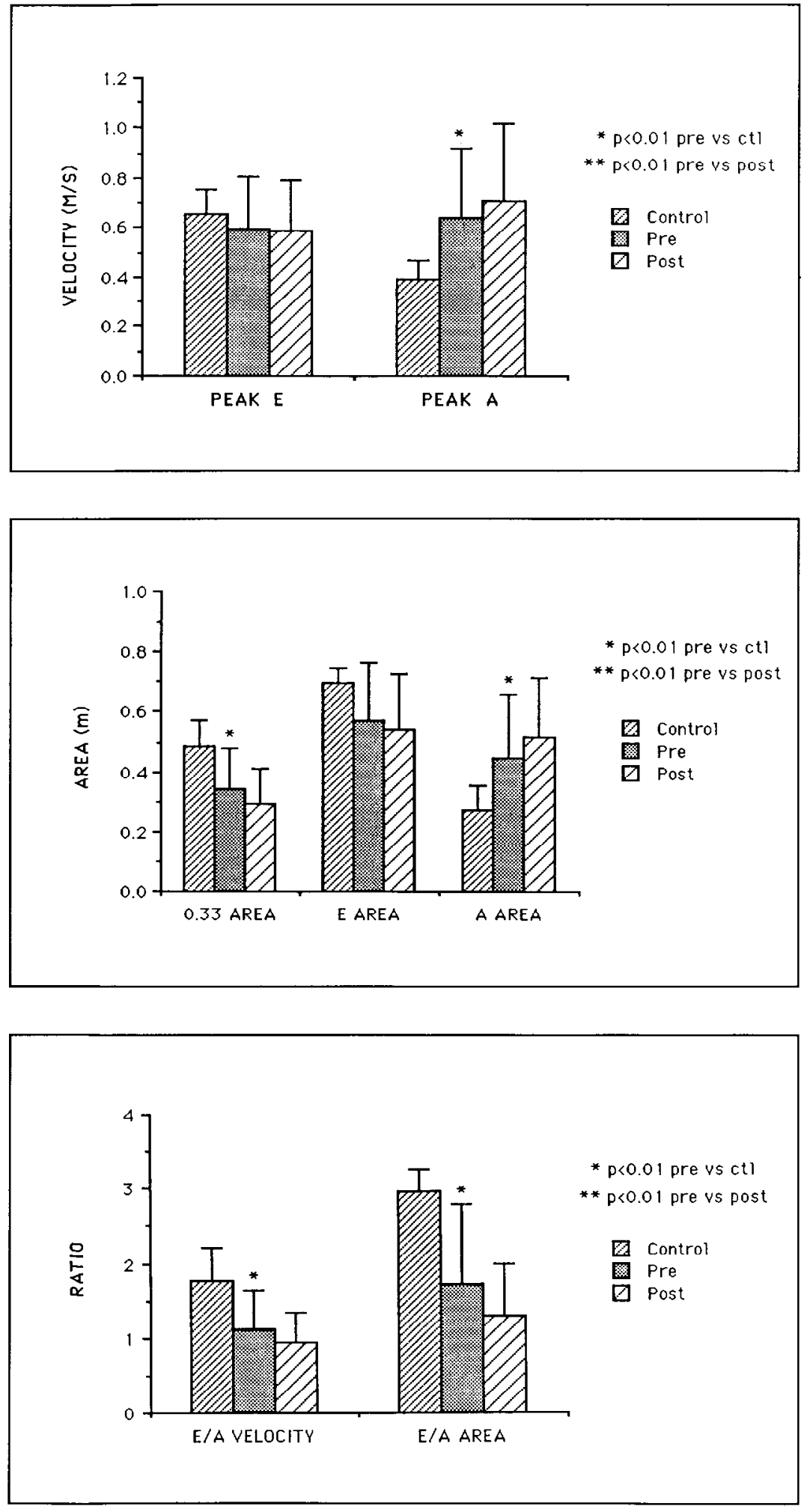

FIGURE 2. Doppler peak velocities measured in control (ct) subjects and patients with pulmonary stenosis (PS) before (pre) and immediately after (post) balloon valvuloplasty. A = veloctly during atrial contraction; $E=$ velocity during rapid ventricular filing.

FIGURE 3. Doppler area fractions in control (ct) subjects and patients with pulmonary stenosis (PS) before (pre) and immediately af ter (post) balioon valuiloplasty. Other abbreviations as in Figure 2.

FIGURE 4. Doppler ratios in control (ct) subjects and patients with pubnonary stenosis (PS) before (pre) and immediately after (post) balloon valviloplasty. Other abbreviations as in Figure 2. 
tions or ratios after successful relief of the PS (Table III).

Figures 2 through 5 summarize the Doppler measurements that were most useful for distinguishing normal subjects from patients with PS.

\section{DISCussion}

Evaluation of RV diastolic function is an important part of the management of many children with congenital heart disease. This study is the first to demonstrate the usefulness of the tricuspid Doppler examination as a technique for assessment of RV diastolic function. In this study, the tricuspid Doppler indexes successfully distinguished the normal RV filling pattern of control subjects from the abnormal RV filling pattern of patients with pressure overload hypertrophy of the right ventricle. In children with PS, the decreased percent of the total Doppler area in the first third of diastole and the increased percent of the total Doppler area under the A wave suggest a relative shift of $R V$ filling to late diastole. These filling abnormalities are identical to those observed for the left ventricle of children with LV outflow obstruction. ${ }^{3}$ In addition, this abnormal tricuspid Doppler pattern resembles the mitral Doppler pattern I observed by Appleton et $\mathrm{al}^{7}$ in patients with impaired LV early diastolic relaxation and normal LV filling pressures. In this study, no patient had a tricuspid Doppler pattern resembling the mitral Doppler pattern II described by Appleton et al' as occurring in patients with markedly elevated filling pressures, an abrupt rapid filling wave and decreased chamber compliance.

From expiration to inspiration in normal children, the mitral peak $\mathrm{E}$ velocity decreases by $8 \%$, the peak $\mathrm{A}$ velocity remains unchanged and the $\mathrm{E} / \mathrm{A}$ ratio decreases by $14 \%$. On the normal tricuspid Doppler recording, however, there are marked changes during respiration. From expiration to inspiration, the tricuspid peak $E$ velocity increases by $26 \%$, the peak $A$ velocity increases by $18 \%$ and the $\mathrm{E} / \mathrm{A}$ ratio remains unchanged. ${ }^{15}$ Thus, when using the tricuspid Doppler recording to assess RV diastolic function, measurements must be made at a standardized time in the respiratory cycle.
Possible mechanisms of diastolic filling abnormalities: In children and adults with pressure overload hypertrophy of the left ventricle, increased wall thickness or mass has been implicated as the cause of impaired $L V$ relaxation. Several studies have shown a significant correlation between the extent of hypertrophy and the severity of the LV diastolic filling abnormality. ${ }^{19-21} \mathrm{RV}$ mass was not assessed in this study due to the lack of an accurate means of measuring it noninvasively; however, all patients in the study group had echocardiographic evidence of severe RV hypertrophy. If RV hypertrophy alone were the cause of impaired RV relaxation, then regression of RV hypertrophy should be accompanied by a return of diastolic filling patterns toward normal. This question could be addressed in long-term studies of patients who have had successful relief of PS. Such a study is currently in progress in our institution.

The afterload during contraction has an effect on the extent of muscle fiber shortening and the rate of fiber lengthening. Failure to normalize RV wall stress (afterload mismatch) could account for the impaired $R V$ relaxation seen in patients with pressure overload hypertrophy. ${ }^{22-24}$ Since RV diastolic filling abnormalities did not return to normal after successful relief of the high afterload, it is unlikely that afterload mismatch was the cause of the filling abnormalities we observed.

Finally, subendocardial ischemia has been suggested to be the cause of impaired relaxation in pressure overload hypertrophy. This may account for the occurrence of impaired relaxation with pressure overload hypertrophy, but not in young athletes with physiologic hypertrophy. ${ }^{25.26}$

Factors affecting the tricuspid valve Doppler indexes: Diastolic indexes of RV relaxation can be influenced by several factors, including age, heart rate and RV loading conditions. Throughout childhood, the tricuspid valve Doppler indexes are independent of age beyond the neonatal period. ${ }^{12-15}$ In the fetus and newborn infant, the peak A velocity normally exceeds the peak $\mathrm{E}$ velocity. ${ }^{14,16,17}$ In this study, the patients and control subjects were age-matched and the study group included no infants $<3$ months of age; therefore, it is unlikely that age contributed to the observed RV diastolic filling
FIGURE 5. Normalized peak filling rates (PFR-SV) in control (ct) subjects and patients with pulmonary stenosis (PS) before (pre) and immediately after (post) balloon valvuloplasty. SV = stroke volume.

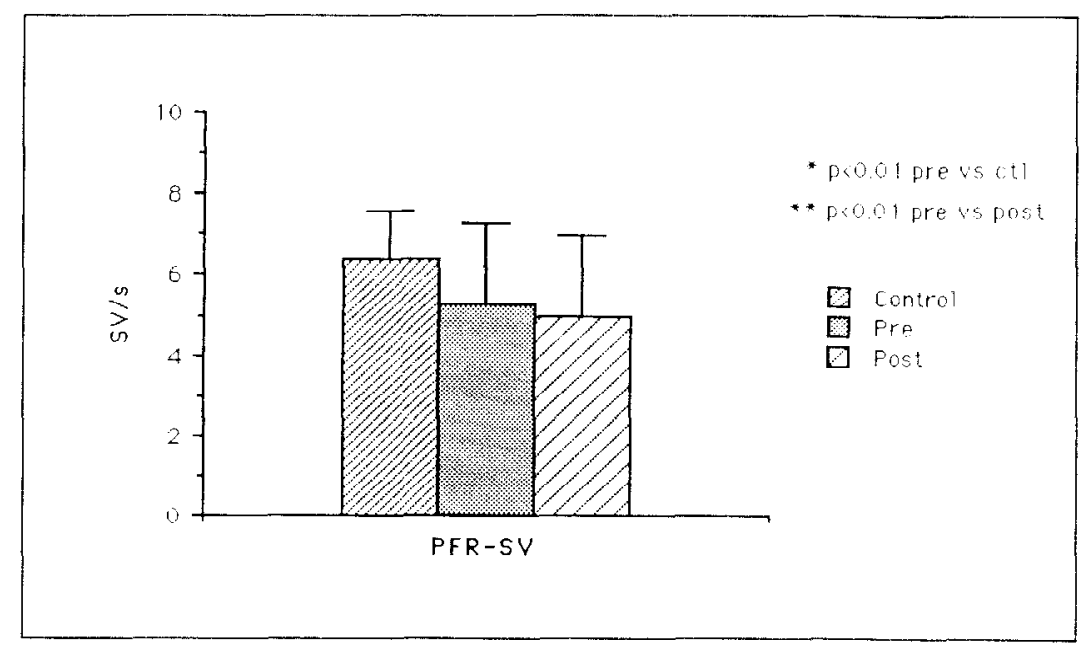


abnormalities. Furthermore, the RV filling abnormalities cannot be explained on the basis of heart rate since the heart rates of the 2 groups were not different. Changes in preload and afterload can alter the tricuspid valve diastolic filling indexes. All children with significant tricuspid or pulmonary regurgitation were excluded from the study since they would be expected to have abnormal RV filling patterns due to increased preload. Finally, RV afterload was not the direct cause of the observed abnormalities in RV filling, as these abnormalities did not improve immediately after successful relief of RV outflow obstruction with balloon valvuloplasty.

\section{REFERENCES}

1. Snider AR, Gidding SS, Rocchini AP, Rosenthal A, Dick M II, Crowley DC Peters J. Doppler evaluation of left ventricular diastolic filling in children with systemic hypertension. Am J Cardiol 1985;56:921-926.

2. Phillips RA, Coplan NL, Krakoff LR, Yeager K, Ross RS, Gorlin R, Goldman ME. Doppler echocardiographic analysis of left ventricular filling in treated hypertensive patients. $J A C C$ 1987,9:317-322.

3. Meliones JM, Snider AR, Serwer GA, Shaffer EM, Rocchini AP, Beekman RH, Rosenthal A, Dick M II, Peters J, Reynolds P. Pulsed Doppler assessment of left ventricular diastolic filling in children with left ventricular outflow obstruction before and after balloon angioplasty. Am J Cardiol 1989;63:231-236.

4. Takenaka AK, Dabestani A, Gardin JM, Russell D, Clark S, Allfie A. Left ventricular filling in hypertrophic cardiomyopathy: a pulsed Doppler echocardiographic study. JACC 1986,7:1263-1271.

5. Gidding SS, Snider AR, Rocchini AP, Peters J, Farnsworth R. Left ventricular diastolic filling in children with hypertrophic cardiomyopathy: assessment with pulsed Doppler echocardiography. JACC 1986;8:310-316.

6. Maron BJ, Spirito P, Green KJ, Wesley YE, Bonow RO, Arce J. Noninvasive assessment of left ventricular diastolic function by pulsed Doppler cchocardiography in patients with hypertrophic cardiomyopathy. $J A C C$ 1987;10:733-742.

7. Appleton CP, Hatle LK, Popp RL. Relation of transmitral flow velocity patterns to left ventricular diastolic function: new insights from a combined hemodynamic and Doppler echocardiographic study. JACC 1988:12:426440.

8. Wind BE, Snider AR, Buda AG, O'Neill WW, Topol EJ, Dilworth LR. Pulsed Doppler assessment of left ventricular diastolic filling in patients with coronary artery disease before and immediately after coronary angioplasty. $\mathrm{Am} \mathrm{J}$ Cardiol 1987;59:1041-1046.

9. Rokey R, Kuo LC, Zoghbi WA, Limacher MC, Quinones MA. Determination of parameters of left ventricular diastolic filling with pulsed Doppler echocardiography: comparison with cineangiography. Circulation 1985771:543-550.

10. Spirito $P$, Maron BJ, Bunow RO. Noninvasive assessment of left ventricular diastolic function: comparative analysis of Doppler echocardiographic and radionuclide angiographic techniques. $J A C C$ 1986;7:518-526.

11. Pearson AC, Goodgold H, Labovitz AJ. Comparison of pulsed Doppler echocardiography and radionuclide angiography in the assessment of left ventricular filling. Am $J$ Cardiol 1988,61:446-454

12. Riggs TW, Rodriguez R, Snider AR, Batton D. Doppler echocardiographic evaluation of right and left ventricular diastolic function in normal neonates. JACC 1989:13:700-705.

13. Hatle L, Angelsen B. Doppler Ultrasound in Cardiology: Physical Principles and Clinical Applications, Second Edition. Philadelphia: Lea and Febiger, $1985 ; 74-96$.

14. Grenadier E, Lima CO, Allen HD, Sahn DJ, Vargas Barron J, Valdes-Cruz LM, Goldberg SJ. Normal intracardiac and great vessel Doppler flow velocities in infants and children. JACC 1984,4:343-350.

15. Riggs TW, Snider AR. Respiratory influence on right and left ventricular diastolic function in normal children. Am $J$ Cardiol 1989.63:858-861.

16. Kenny JF, Plappert T, Doubilet P, Saltzman DH, Cartier M, Zollars L, Leatherman GF, St. John Sutton MG. Changes in intracardiac blood flow velocities and right and left ventricular stroke volumes with gestational age in the normal human fetus: a prospective Doppler echocardiographic study. Circulation 1986;74:1208-1216

17. Huhta JC, Strasburger JF, Carpenter RJ, Reiter A, Abinader E. Pulsed Doppler fetal echocardiography. $J$ Clin Ulirasound 1985:13:247-254.

18. Bowman LK, Forrester AL, Jaffe CC, Mattera J, Wackers FJT, Zaret BL. Peak filling normalized to mitral stroke volume: a new Doppler echocardiographic filling index validated by radionuclide angiographic techniques. JACC 1988; 12:937-943.

19. Fifer MA, Borow KM, Colan SD, Lorell BH. Early diastolic left ventricular function in children and adults with aortic stenosis. JACC 1985:5:1/47-1154. 20. Eichhorn P, Grimm J, Koch R, Hess O, Carroll J, Krayenbuehl HP. Left ventricular relaxation in patients with left ventricular hypertrophy secondary to aortic valve disease. Circulation 1982,65:1395-1404.

21. Murakami R, Hess OM, Gage JE, Grimm J, Drayenbuehl HP. Diastolic filling dynamics in patients with aortic stenosis. Circulation 1986;73:1162-1174. 22. Grossman W, McLaurin LP. Diastolic properties of the left ventricle. Ann Intern Med 1976,84:316-326.

23. Glantz SA, Parmley WW. Factors which affect the diastolic pressure-volume curve. Circ Res 1978:42:171-180.

24. Tamiya $K$, Sugawara $M$, Sakurai $Y$. Maximum lengthening velocity during isotonic relaxation at preload in canine papillary muscle. $A m J$ Physiol 1979;237:H83-H89.

25. Lorell BH, Grossman W. Cardiac hypertrophy: the consequences for diastole. JACC 1987,9:1189-1193.

26. Colan SD, Sanders SP, McPherson D, Borow KM. Left ventricular diastolic function in elite athletes with physiologic cardiac hypertrophy. JACC 1985,6:545549. 